\title{
FORMATION OF A HEALTHY LIFESTYLE CULTURE AMONG STUDENTS
}

\author{
Jumanova F.U
}

Candidate Of Pedagogical Sciences, Chirchik State Pedagogical Institute Of Tashkent, Uzbekistan

Jumanov A.M

Teacher, Tashkent State University Of Physical Culture And Sports, Uzbekistan

\section{ABSTRACT}

The relevance of the scientific research carried out in this work lies in the fact that the most important practical task of public health is the prevention of modern human diseases and the provision of conditions for improving the health of each person and the entire population as a whole.

KEYWORDS:- Practical task, health, human, diseases, population, lifestyle.

\section{INTRODUCTION}

The novelty of the work lies in the idea of students' health, which is closely related to the understanding of the need to strengthen it based on the achievements of modern science, which has justified the possibility of active development of adaptive abilities inherent in it by nature itself and the development of which depends on the physical exertion of the body.

A distinctive feature of the life activity of a modern student, generated by scientific and technological progress, is a significant change in the rhythm and lifestyle. This is characterized, first of all, by a very noticeable limitation of the specific weight of physical labor in everyday life, at work and an increase in the disparity between significant intellectual and mental loads, on the one hand, and a sharp decrease in physical activity, on the other.

The practical significance of this work is to substantiate the need for targeted health promotion of students of different age groups.

The urgency of the problem is confirmed by the fact that today society needs the formation of a person who is aware of the value of health, who is able to organize activities for its preservation and strengthening, focused on maintaining a healthy lifestyle that excludes causing any harm to their health and the health of others.

Nowadays, one of the main approaches to the definition of health is a functional approach that studies a person's ability to perform natural biological and inherent social functions, and more specifically, the ability to perform activities useful for himself and for the whole society.

It is known that the level of human health depends on many factors: hereditary, socio- 
CURRENT RESEARCH JOURNAL OF PEDAGOGICS 2(11): 60-63, November

2021 DOI: https://doi.org/10.37547/pedagogics-crjp-02-11-13

ISSN 2767-3278

(C)2021 Master Journals

Crossref doi) 81 Google

Accepted 25th November, 2021 \& Published 30 ${ }^{\text {th }}$ November, 2021

economic, environmental, health system activities. But, according to WHO, it is only 10 $15 \%$ related to the latter factor, $15-20 \%$ is due to genetic factors, $25 \%$ is determined by environmental conditions and $50-55 \%$ by human conditions and lifestyle $(4,1,2)$.

Thus, it is obvious that the primary role in the preservation and formation of health still belongs to the person himself, his lifestyle, his values, attitudes, the degree of harmonization of his inner world and relationships with the environment.

Strengthening and creating health should become the need and responsibility of every person.

In the system of universal cultural values, a high level of health and physical fitness of a person largely determines the possibility of mastering all other values and in this sense is the basis without which the process of harmonious human development is ineffective.

A healthy lifestyle is not only a physical basis, but also a special way of thinking, a slightly different view of everyday things. It is based on the principles of morality, rational organization, and an active life position.

A healthy lifestyle is formed from many components, and each component is important in its own way. Ignoring even one of them can negate all other efforts.

The value attitude to one's health, the need for a healthy lifestyle and the ability to take care of one's health are the tasks that parents and teachers face.

The formation of a healthy lifestyle is a complex problem. We cannot talk only about ways and methods of health promotion, disease prevention. It is necessary to increase the role of personal qualities in the conscious and strongwilled acceptance of the principles of a healthy lifestyle, and health care, its strengthening should become value motives of behavior.

The problem of a healthy lifestyle is closely related to the problem of physiological adaptation of students $(3,5,7)$. The physiological adaptation of the human body proceeds involuntarily and unconsciously. However, the success of social adaptation and adaptation of students to the new educational environment largely depends on this process (8).

Let's consider this problem on the example Chirchik State Pedagogical Institute of the Tashkent region.

In the course of the study, we tried to find out how the culture of a healthy lifestyle of university students is formed and what are the main factors contributing to its formation.

This was the main purpose of our research.

The objectives of the study included: to assess the health status of students, to identify how they relate to a healthy lifestyle and to their health, to study the factors that interfere with, as well as contribute to the formation of a healthy lifestyle culture, to outline ways to solve the problem.

\section{Materials AND METHOdS OF RESEARCh}

The main research methods were questionnaires and processing of the obtained data. 28 respondents participated in the survey, of which 19 were female and 9 were male.

The object of research: third-year students, aged 20 to 21 years. The majority of respondents (21) live in a dormitory and only a small part (7) live in rented apartments or with their parents.

\section{RESULTS AND THEIR DISCUSSION}

Considering the indicators characterizing the state of health of students, we are forced to state disappointing facts. Only 5 people $(17.86 \%)$ out of 28 respondents rate their level of health as high and consider themselves absolutely healthy. The remaining respondents $(82.14 \%)$ suffer 
CURRENT RESEARCH JOURNAL OF PEDAGOGICS 2(11): 60-63, November

2021 DOI: https://doi.org/10.37547/pedagogics-crjp-02-11-13

ISSN 2767-3278

(C)2021 Master Journals

\section{Crossref dof 81 Google}

Accepted 25th November, 2021 \& Published 30 ${ }^{\text {th }}$ November, 2021

from chronic diseases or have minor health abnormalities. Quite a large number of students $(32.14 \%)$ are prone to frequent colds. There are also students whose health does not allow them to attend academic physical education classes at the university (28.57\%). The main reason for the release of such young people is serious diseases of the visual organs, organs of the cardiovascular system, musculoskeletal system.

Another addiction among students has appeared in the last decade - this is a long stay at gadgets and a computer. So, $92.86 \%$ of the respondents spend a long time (3-5 hours on weekdays, 5-8 hours on weekends) at the computer (this is not always the time spent on learning curricula). All this also cannot but negatively affect the health of students.

So, girls and boys, students, generally do not differ in good health. But at the same time, we must admit that they are positive about leading a healthy lifestyle (85.71\%).

Young people believe that their professional activity largely depends on maintaining a healthy lifestyle, what success they will achieve in it, especially since it is not easy in modern conditions, with an unstable economic situation.

A significant part of the respondents also understand that students themselves are responsible for their health: it depends, first of all, on themselves, on their lifestyle (53.57\%), and only then on external factors.

It should also be noted that in the behavior of those who try to adhere to a healthy lifestyle, there is no consistency, consistency, it is often done from case to case, irregularly.

Among the main reasons preventing students from joining a healthy lifestyle, the interviewed students name mainly such: own laziness (71.43\%), lack of time (60.71\%), lack of money (32.14\%), weak willpower (28.57\%), lack of motivation (17.86\%).
Students prefer to avoid visiting medical institutions, go to the doctor only if they get seriously ill, only 4 people go to the doctor every six months or a year for preventive purposes (14.29\%).

It should be noted that it is the ailments that most often force young people to adhere to a healthy lifestyle: for example, students who have problems in the digestive system (gastrointestinal tract), try to eat properly and rationally, observe, if necessary, a diet, avoid a long break in eating, and even more so do not allow evening overeating and night snacks. Proper, rational nutrition is typical only for 6 respondents $(21.43 \%)$.

Conclusion. Special attention should now be paid to the formation of a healthy lifestyle of students. It is necessary to encourage students to preserve and strengthen their health, promote and maintain a healthy lifestyle culture among young people, cultivate their a kind of "fashion" for health, to introduce into the educational process knowledge aimed at forming a healthy lifestyle from an early age. Well-organized promotion of medical and hygienic knowledge contributes to the reduction of diseases, helps to bring up a healthy, physically strong generation. It is necessary in the educational process to pay an important role to the education of students' attitude to health as the main human value.

\section{Conclusions}

Based on the above, we can conclude about the relevance of the problem of a healthy lifestyle of young people. Therefore, we decided to conduct a study on this topic and find out how young people and girls today relate to their health and to a healthy lifestyle in general.

Thus, the analysis of the data obtained during the study practically confirmed the situation that is widespread throughout the country: the culture of a healthy lifestyle of students is at a level close 
CURRENT RESEARCH JOURNAL OF PEDAGOGICS 2(11): 60-63, November

2021 DOI: https://doi.org/10.37547/pedagogics-crjp-02-11-13

ISSN 2767-3278

(C)2021 Master Journals

Crossref do) 81 Google

Accepted 25th November, 2021 \& Published 30th November, 2021

to low.

Based on all of the above, we can say that the formation of a healthy lifestyle culture of students today should become one of the priority tasks of pedagogical activity of universities.

It is necessary to coordinate the activities of all participants in the educational process, the teaching staff, first of all, as well as psychologists, medical workers, etc.

Much attention should be paid to the restructuring of the students' value system, the formation of motivation for self-preservation behavior. But, first of all, it is necessary to educate a person as a person who is responsible for his life, knows how to foresee the consequences of his actions, has a high level of self-discipline and self-control.

\section{REFERENCES}

1. AbdurakhmanovK.Kh., KhudaikulovSh.Kh. the foundation of future is healthy life Tashkent, 2020. - $168 \mathrm{p}$.

2. Abdurakhmanov K.H. Physical culture and a healthy lifestyle: A methodological guide.Chirchik:UzGUFKS,2019.256p.

3. Weiner E.N. General valeology. Lipetsk: Pedagogue, 1998. - 168 p.

4. Gatilo V.L. Diagnostics of social health of students// Central Russian Bulletin of Social Sciences. 2013. No. 4. pp. 20-26.

5. Health culture and life safety: collection of scientific tr. participants of the All-Russian Conference. [from the international participation] "Health culture and life safety", September 12-13, 2006, Balashov / ed. by A.V. Timushkin. - Balashov :Nikolaev, 2006- $196 \mathrm{p}$.

6. Kazin, E. M. The problem of preserving the health and development of students in the education system in the conditions of its modernization (on the example of Kuzbass) [Text] / E. M. Kazin, A. I. Fedorov, S. I. Petukhov // Valeology. - 2002. - No. 2.Smirnov, N. K. Guide to health-saving pedagogy of health-saving education technology [Text] / N. K. Smirnov. - M.: Publishing House of the ARCTIC, 2008. - 288 p.

7. Semenchenko V.V., ShchegolevYu.A. Physical education of youth with the help of sports games //Scientific and methodological electronic journal "Concept". 2014. Vol.26. pp.156-160. 